\title{
Electrochemical Regeneration of GIC Adsorbent in a Continuous Electrochemical Reactor
}

\author{
S. N. Hussain, H. M. A. Asghar, H. Sattar, and E. P. L. Roberts
}

\begin{abstract}
Arvia ${ }^{\mathrm{TM}}$ introduced a novel technology consisting of adsorption followed by electrochemical regeneration with a graphite intercalation compound adsorbent that takes place in a single unit. The adsorbed species may lead to the formation of intermediate by-products products due to incomplete mineralization during electrochemical regeneration. Therefore, the investigation of breakdown products due to incomplete oxidation is of great concern regarding the commercial applications of this process. In the present paper, the formation of the chlorinated breakdown products during continuous process of adsorption and electrochemical regeneration based on a graphite intercalation compound adsorbent has been investigated.
\end{abstract}

Index Terms-Adsorption, electrochemical regeneration, chlorphenols.

\section{INTRODUCTION}

Activated carbon has been widely and effectively used for the removal of contaminants, organic in nature, from wastewater [1], [2]. Once the activated carbon has been exhausted, it must be either disposed off or be regenerated for reuse. A variety of regeneration techniques are available including chemical/solvent [3], microbial [4], wet air oxidation [5], ultrasonic [6] and thermal regeneration [7]. Nevertheless, thermal regeneration of activated carbon is a costly process. Among the alternatives, electrochemical regeneration has gained considerable significance in recent years since onsite removal and mineralization of adsorbed species is possible in this technique. In this context, about 80-90\% regeneration efficiencies have been reported for the electrochemical regeneration of activated carbon [8], [9]. On the other hand, the high operating costs due to high cell voltages associated with relatively low electrical conductivity of activated carbon is one of the main disadvantages of electrochemical regeneration. In addition, the porous morphology of activated carbon gives long adsorption times. In order to deal with the issues related to the electrochemical regeneration of activated carbon, a novel and unique process of wastewater treatment was developed at University of the Manchester. This technique is based in exploiting graphite intercalation compound (GIC) based adsorbents for the adsorption of low concentrations of organic pollutants present in wastewater followed by its electrochemical regeneration in an electrochemical reactor.

Manuscript received February 30, 2014; revised October 3, 2014.

S. N. Hussain, H. M. A. Asghar, and H. Sattar are with Institute of Chemical Engineering and Technology, University of the Punjab, Lahore, Pakistan (e-mail: hussain_nadir@hotmail.com).

E. P. L. Roberts is with Department of Chemical and Petroleum Engineering, University of Calgary, Calgary AB, T2N 1N4 Canada.
In comparison to activated carbon, the GIC adsorbent has a smooth surface morphology and thus possesses low adsorption capacity. However, the adsorption kinetics of these materials is very fast [10], [11]. The higher electrical conductivity of the GIC material has made it an appropriate material for electrochemical regeneration. The Arvia ${ }^{\circledR}$ technology Ltd is a University of Manchester's spin out company that has exploited GIC adsorbents for the treatment of wastewater containing low concentrations of refractory and toxic contaminants [12], [13].

In an ideal electrochemical regeneration method, the species adsorbed onto the adsorbent surface should be completely mineralized into $\mathrm{CO}_{2}$ and $\mathrm{H}_{2} \mathrm{O}$ [14]. Previous studies based on the electrochemical regeneration of phenol loaded graphitic adsorbents, have shown that some intermediate oxidation/by-products could also be generated during batch as well as continuous processes that depends mainly on the regeneration conditions [15], [16]. In this context, a number of non-chlorinated phenolic intermediate oxidation products including hydroquinone, benzoquinone, maleic and oxalic acid have been detected in relatively small concentrations in comparison the concentration of phenol present in the water to be treated [15]. Batch studies carried out in a simple electrochemical reactor has shown that the major mechanism responsible for the generation of these intermediate products was found to be associated with the indirect oxidation of phenol during the electrochemical regeneration of the phenol loaded adsorbent. In the present study, the formation of the chlorinated breakdown products in a continuous electrochemical reactor has been investigated. Phenol was selected as a model contaminant for adsorption onto GIC adsorbent followed by its electrochemical regeneration in a continuous electrochemical reactor.

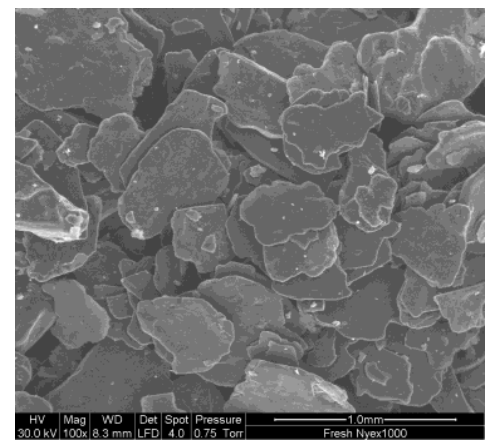

Fig. 1. Scanning electron micrograph of GIC particles [4].

\section{MATERIALS AND METHODS}

\section{A. Materials}

The GIC adsorbent material was supplied in the form of 
flakes by Arvia Technology Ltd. As stated above, this is a non-porous material with flat morphology as shown in Fig. 1. The flakes have a mean particle diameter of around 485 $\mu \mathrm{m}$. The BET surface area of the material is $1.0 \mathrm{~m}^{2} / \mathrm{g}$.

Analytical grades of phenol, chlorphenols and other chemicals used in these experimenst were supplied by Sigma-Aldrich $^{\circledR}$, UK.

\section{B. Continuous Unit of Adsorption and Electrochemical Regeneration}

Fig. 2 shows a unit that is used for carrying out the adsorption with electrochemical regeneration continuously in the same equipment. However, the adsorption and electrochemical regeneration takes place in separate zones as shown in the Fig. 2. The details of the reactor have been described elsewhere [15].

The continuous unit is made from polycarbonate material. The internal dimensions of the reactor are $35 \mathrm{~cm}$ wide, 2.2 $\mathrm{cm}$ deep and $147 \mathrm{~cm}$ tall. The adsorption zone is composed of two symmetrical side zones, each with a dimension of 10 $\mathrm{cm}$ by $2.2 \mathrm{~cm}$ [15]. The regeneration zone consists of an anode and cathode that is being divided by a polymeric membrane. A bed of adsorbent particles flows downward along the anode of the regeneration zone. The anode of the reactor is composed of an iridium/ruthenium mixed metal oxide coated titanium plate (supplied by Electrode Products Technology Ltd., UK) and the cathode is made up of a perforated stainless steel plate [15]. Each of the electrodes is $12 \mathrm{~cm}$ wide by $60 \mathrm{~cm}$ in height.

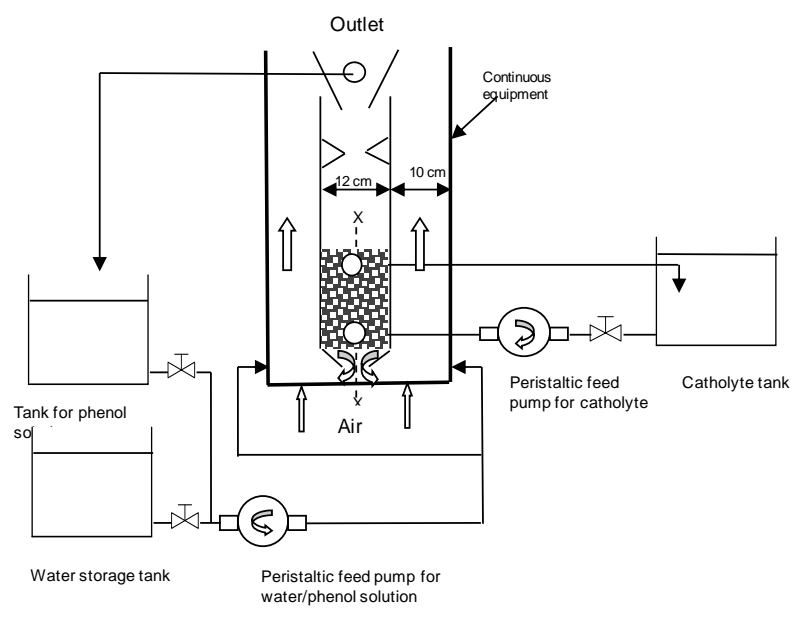

Fig. 2. A sketch of a continuous reactor employed for adsorption and electrochemical regeneration [15].

As mentioned before, a microporous polyethylene membrane (Daramic GmbH, Germany) separates the adsorbent from the stainless steel cathode [15]. Air is injected at the bottom of the adsorption zone through a set of fourteen injection nozzles in order to produce mixing and to continuously circulate the GIC adsorbent throughout the unit. The flow rate of air is controlled in such a way that the injected air entrains the GIC particles from the bottom of the regeneration zone into the adsorption zones. In this manner, a uniform bed movement is attained.

The water to be treated is being introduced close to the bottom of the adsorption zones. The air bubbles disengage at the top of the adsorption zones and the water flows into a settlement zone and thereby, the adsorbed GIC particles settles from the upward flowing water that has been treated at this stage. The GIC adsorbent particles settle in the centre of the unit due to their high density that leads to the formation of a moving bed between the anode and membrane [15].

\section{Methods}

Initially, clean water was filled in the electrochemical reactor as shown in Fig. 2. In the cathode compartment, an aqueous acidified solution of sodium chloride at $\mathrm{pH}$ around 1 was circulated as shown in Fig. 2. A mass of $2.5 \mathrm{~kg}$ of the adsorbent was present in the reactor. The adsorbent was allowed to circulate in the adsorption zones by injecting air through the nozzles located at the bottom of the reactor as shown in Fig. 2.

The GIC adsorbent was thoroughly cleaned for about 2-3 hours by running tap water at a current of $7 \mathrm{~mA} \mathrm{~cm}^{-2}$. Water

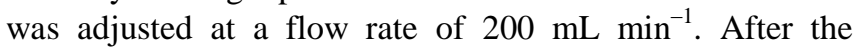
cleaning of the adsorbent, the water supply was stopped and the feed was diverted to a container that contained $25 \mathrm{~L}$ of $500 \mathrm{mg} \mathrm{L}^{-1}$ of phenol solution. The outlet from the reactor was also diverted towards phenol solution container i.e the solution was allowed to flow through the electrochemical reactor in recirculation mode. Following conditions were maintained during the experimentation.

- $\quad$ Water flow rate $=380 \mathrm{~mL} \mathrm{~min}^{-1}$

- Phenol concentration $=500 \mathrm{ppm}$

- Current density $=0.007 \mathrm{~A} \mathrm{~cm}^{-2}$

- $\quad$ Air flow rate $=4.8 \mathrm{~L} \mathrm{~min}^{-1}$

Samples of the water were taken from the reactor outlet after regular intervals of time.

\section{Analysis}

High pressure liquid chromatography equipped with an ultraviolet detector was employed to analyze the water samples collected from the reactor outlet as mentioned above. A column with $\mathrm{C} 18$ stationary phase was used for the analysis of chlorinated breakdown products of phenol. The mobile phase was consisted of HPLC grade water and acetonitrile containing $0.01 \mathrm{M} \mathrm{H}_{3} \mathrm{PO}_{4}$. The oven was kept at a temperature of $35^{\circ} \mathrm{C}$, and ultraviolet detection was carried out at $230 \mathrm{~nm}$.

The gradient of the mobile phase used is given in Table I:

TABLE I: GRADIENT OF THE WATER AND ACETONITRILE USED AS MOBILE PHASE FOR THE HPLC DETERMINATION OF CHLORPHENOLS [16]

\begin{tabular}{|c|c|c|}
\hline Time $(\min )$ & \% Water & \% Acetonitrile \\
\hline 0 & 80 & 20 \\
\hline 20 & 55 & 45 \\
\hline 15 & 20 & 80 \\
\hline
\end{tabular}

\section{RESULTS AND DISCUSSIONS}

Several intermediate oxidation products were found during the electrochemical regeneration of the adsorbent loaded with phenol in batch and continuous process [15][17]. These products include aromatic and aliphatic intermediate oxidation products of phenol such as hydroquinone, benzoquinone, catechol, maelic and oxalic acids. The formation of these products was largely related to the indirect of electrochemical oxidation of phenol solution present with the GIC adsorbent. However, chlorinated 
breakdown products released in water poses serious environmental concerns because normally these compounds are carcinogenic in nature. The present study is focused on the investigation regarding the generation of chlorinated byproducts in water during the continuous process of adsorption with electrochemical regeneration employing graphitic adsorbent.

In this context, small concentrations of monochlorphenols were formed during the first few hours of continuous operation and these were observed to be decreased afterwards, as shown in Fig. 2. Furthermore, very small concentrations of dichlorophenols were also detected during the continuous process as shown in Fig. 3. The concentrations of the mono-chlorphenols increased in the initial 8 hours in the reactor outlet. At around 10 hours of operation, the concentrations of mono-chlorophenols started to decrease with minor concentrations observed after $20 \mathrm{~h}$. The relatively low concentrations of chlorinated intermediate oxidation products during the continuous electrochemical regeneration could be due to the low current density used in these experiments in comparison to the concentrations of non-chlorinated aromatic intermediates reported in the previous studies [15], [17].

The continuous process employing adsorption with electrochemical regeneration was further investigated by assuming that mono-chlorphenols were the main chlorinated intermediate products generated during regeneration. The percentage of chlorphenols formed in comparison to the percentage of phenol removed was calculated as follows [15], [18]:

$$
\% \text { Aromatics }=\frac{[\text { Chlorophenols }]}{(\text { Phenol })_{\mathrm{o}}-(\text { Phenol })_{\mathrm{t}}} \times 100
$$

where [chlorphenols]t is the concentration of monochlorphenols in $\mathrm{mmol} \mathrm{dm}^{-3}$ present at time $(\mathrm{t})$. (Phenol) $)_{0}$ and (phenol)t are the concentrations of phenol at zero and at $t$ time in $\mathrm{mmol} \mathrm{dm}^{-3}$.

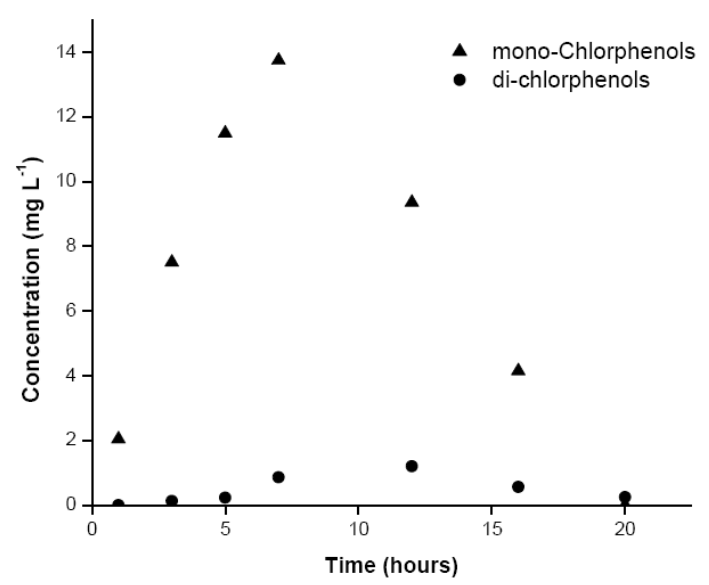

Fig. 3. Concentrations of chlorphenols during continuous adsorption and electrochemical regeneration for $500 \mathrm{mg} \mathrm{L}^{-1}$ phenol solution at $7 \mathrm{~mA} \mathrm{~cm}^{-2}$.

The data in Fig. 4 shows that approximately $4 \%$ of the phenol was converted to chlorophenols during the first $10 \mathrm{~h}$, but after this the percentage converted to chlorophenols fell close to zero after $20 \mathrm{~h}$ of treatment. This suggests that less phenol is converted to chlorinated breakdown products compared to the formation of non-chlorinated products that has been reported in the previous studies [15]. In addition, chlorophenols are known to have a higher adsorptive capacity than phenol and its non-chlorinated intermediates including benzoquinone and thus they are likely to be preferentially adsorbed on the GIC adsorbent. Adsorption may be followed by the oxidation of these species on the surface of adsorbent during electrochemical regeneration leading to a solution with almost negligible concentrations of chlorphenols.

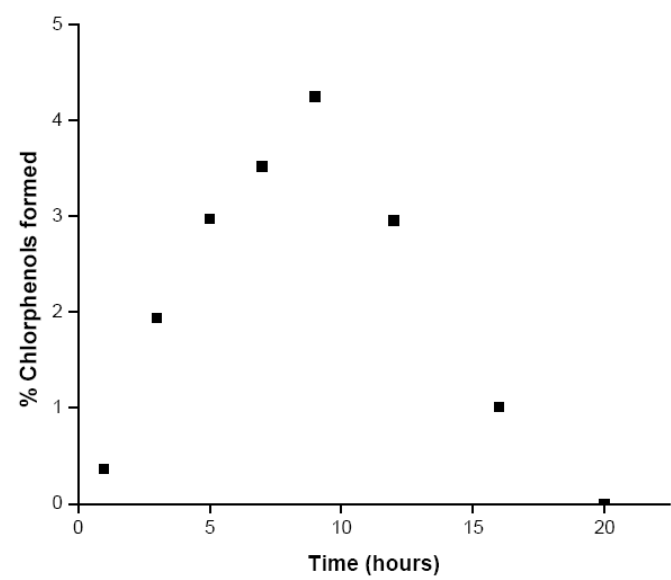

Fig. 4. Trend of the percentage of chlorphenols formed during the continuous electrochemical regeneration.

\section{CONCLUSIONS}

The continuous process of adsorption with electrochemical regeneration using GIC adsorbent has shown that significantly low concentrations of monochlorphenols and di-chlorphenols were observed in comparison to the starting concentration of phenol solution $\left(500 \mathrm{mg} \mathrm{L}^{-1}\right)$. The relatively low concentrations of chlorophenols observed were probably due to the relatively

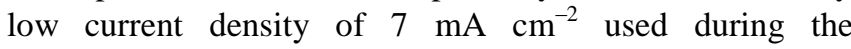
continuous operation. These results have important implications regarding the commercial application of the process of adsorption and electrochemical regeneration.

\section{ACKNOWLEDGMENTS}

The authors acknowledge the financial and material support provided by Arvia Technology Ltd. We are also thankful to the University of Manchester and Punjab University, Lahore for their support for this research.

\section{REFERENCES}

[1] J. C. Crittenden, R. R. Trussell, D. W. Hand, K. J. Howe, and G. Tchobanoglous, Water Treatment: Principles and Design. $2^{\text {nd }}$ edition. John Wiley and Sons, Inc., 2005.

[2] A. Dabrowski, Adsorption and Its Applications in Industry and Environmental Protection, Netherlands: Elsevier Science B.V., 1999.

[3] T. Sutikno and K. J. Himmeistein, "Desorption of phenol from activated carbon by solvent regeneration," Ind. Eng. Chem. Fundam, vol. 22 , no. 4 , pp. 420-425, 1983 .

[4] D. H. Hutchinson and C. W. Robinson, "A microbial regeneration process for granular activated carbon-1. Process modelling," Water Research, vol. 24, no. 10, pp. 1209-1215, 1990

[5] R. V. Shende and V. V. Mahajani, "Wet oxidative regeneration of activated carbon loaded with reactive dye," Waste Management, vol. 22, pp. 73-83, 2002

[6] J. L. Lim and M. Okada, "Regeneration of granular activated carbon using ultrasound," Ultrasonics Sonochemistry, vol. 12, pp. 277-282, 2005 . 
[7] G. S. Miguel, S. D. Lambert, and N. J. D. Graham, "The regeneration of field-spent granular activated carbons," Water Research, vol. 35, no. 11 , pp. $2740-2748,2001$.

[8] R. M. Narbaitz and J. Cen, "Electrochemical regeneration of granular activated carbon," Water Research, vol. 28, no. 8, pp. 1771-1778, 1994.

[9] Z. Minghua, D. Qizhou, L. Lecheng, and W. Dahui, "Activated carbon adsorption- advanced electro-oxidative regeneration for the treatment of biorefractory organic pollutants," Chinese Science Bulletin, vol. 50, no. 5, pp. 489-491, 2005

[10] N. W. Brown, E. P. L. Roberts, A. A. Garforth, and R. A. W. Dryfe, "Electrochemical regeneration of a carbon-based adsorbent loaded with crystal violet dye," Electrochimica Acta, vol. 49, no. 20, pp. 3269-3281, 2004.

[11] N. W. Brown, E. P. L. Roberts, A. Chasiotis, T. Cherdron, and N. Sanghrajka, "Atrazine removal using adsorption and electrochemical regeneration," Water Research, vol. 38, no. 13, pp. 3067-3074, 2004.

[12] K. T. Eccleston, N. W. Brown, E. P. L. Roberts, and J. L. Richards, "Adsorbents for treating contaminated liquids," US Patent 2009/0321361 A1, 2009.

[13] K. T. Eccleston, A. J. Eccleston, J. L. Richards, N. W. Brown, and E P. L. Roberts, "Apparatus for the electrochemical regeneration of adsorbents," US Patent 7790024 B2, 2010.

[14] N. W. Brown and E. P. L. Roberts, "Electrochemical pre-treatment of effluents containing chlorinated compounds using an adsorbent," Journal of Applied Electrochemistry, vol. 37, no. 11, pp. 1329-1335, 2007.
[15] S. N. Hussain, E. P. L. Roberts, H. M. A. Asghar, A. K. Campen, and N. W. Brown, "Oxidation of phenol and adsorption of breakdown products using a graphite adsorbent with electrochemical regeneration," Electrochimica acta, vol. 92, pp. 20-30, 2013

[16] S. N. Hussain, "Water treatment using graphite adsorbents with electrochemical regeneration," $\mathrm{PhD}$ thesis, University of the Manchester, UK, 2012

[17] S. N. Hussain, H. M. A. Asghar, A. K. Campen, N. W. Brown, and E. P. L. Roberts, "Break down products formed due to oxidation of adsorbed phenol by electrochemical regeneration of a graphite adsorbent," Electrochimica acta, 2013.

[18] J. Iniesta, M. A. Michaud, M. Panizza, G. Cerisola, A. Aldaz, and C. Comninellis, "Electrochemical oxidation of phenol at boron-doped diamond electrode," Electrochimica Acta, vol. 46, pp. 3573-3578, 2001.

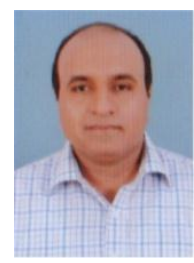

Syed Nadir Hussain has B.Sc. M.Sc \& PhD degree in chemical engineering. He is an assistant professor at the Institute of Chemical Engineering \& Technology, University of the Punjab, Lahore, Pakistan. He is supervising various research projects in chemical engineering. His areas of interest include waste water treatment by adsorption and electrochemical regeneration. 
